\title{
BMJ Open Developing evidence-based recommendations for optimal interpregnancy intervals in high-income countries: protocol for an international cohort study
}

\author{
M Luke Marinovich, ${ }^{1}$ Annette K Regan, ${ }^{2}$ Mika Gissler, ${ }^{3,4}$ Maria C Magnus, ${ }^{5,6,7}$ \\ Siri Eldevik Håberg, ${ }^{7}$ Amy M Padula, ${ }^{8}$ Jonathan A Mayo, ${ }^{9}$ Gary M Shaw, ${ }^{9}$ \\ Stephen Ball, ${ }^{10}$ Eva Malacova, ${ }^{1}$ Amanuel T Gebremedhin, ${ }^{1}$ Natasha Nassar, ${ }^{11}$ \\ Cicely Marston, ${ }^{12}$ Nick de Klerk, ${ }^{13}$ Ana Pilar Betran, ${ }^{14}$ Gavin F Pereira ${ }^{1}$
}

To cite: Marinovich ML, Regan AK, Gissler M, et al. Developing evidence-based recommendations for optimal interpregnancy intervals in high-income countries: protocol for an international cohort study. BMJ Open 2019;9:e027941. doi:10.1136/ bmjopen-2018-027941

- Prepublication history and additional material for this paper are available online. To view these files, please visit the journal online (http://dx.doi. org/10.1136/bmjopen-2018027941).

Received 16 November 2018 Revised 23 November 2018 Accepted 23 November 2018

Check for updates

(C) Author(s) (or their employer(s)) 2019. Re-use permitted under CC BY. Published by BMJ.

For numbered affiliations see end of article.

Correspondence to Dr M Luke Marinovich; luke.marinovich@curtin.edu.au

\section{ABSTRACT}

Introduction Short interpregnancy interval (IPI) has been linked to adverse pregnancy outcomes. WHO recommends waiting at least 2 years after a live birth and 6 months after miscarriage or induced termination before conception of another pregnancy. The evidence underpinning these recommendations largely relies on data from low/middleincome countries. Furthermore, recent epidemiological investigations have suggested that these studies may overestimate the effects of IPI due to residual confounding. Future investigations of IPI effects in high-income countries drawing from large, population-based data sources are needed to inform IPI recommendations. We aim to assess the impact of IPIs on maternal and child health outcomes in high-income countries.

Methods and analysis This international longitudinal retrospective cohort study will include more than 18 million pregnancies, making it the largest study to investigate IPI in high-income countries. Populationbased data from Australia, Finland, Norway and USA will be used. Birth records in each country will be used to identify consecutive pregnancies. Exact dates of birth and clinical best estimates of gestational length will be used to estimate IPI. Administrative birth and health data sources with $>99 \%$ coverage in each country will be used to identify maternal sociodemographics, pregnancy complications, details of labour and delivery, birth and child health information. We will use matched and unmatched regression models to investigate the impact of IPI on maternal and infant outcomes, and conduct metaanalysis to pool results across countries.

Ethics and dissemination Ethics boards at participating sites approved this research (approval was not required in Finland). Findings will be published in peer-reviewed journals and presented at international conferences, and will inform recommendations for optimal IPI in high-income countries. Findings will provide important information for women and families planning future pregnancies and for clinicians providing prenatal care and giving guidance on family planning.

\section{Strengths and limitations of this study}

- With data from four countries and over 18 million pregnancies, this will be the largest cohort study to investigate IPI in high-income countries.

- The size of this cohort will allow strict control for confounding through matching multiple pregnancies within women, and permit the investigation of IPI effects among subpopulations.

- Collaboration between countries and the use of individual-level data will minimise methodological heterogeneity.

- Data items such as socioeconomic status vary between countries in their completeness and their method of measurement, limiting the extent to which such variables may be incorporated as covariates.

- Data on early pregnancy loss are poorly or inconsistently captured in routine data collection, which may result in misclassification of IPI.

\section{INTRODUCTION}

Interpregnancy interval (IPI), or the time from birth to conception of the next pregnancy, has been identified as a potentially modifiable risk factor linked to adverse perinatal outcomes. Currently, WHO recommends that women wait at least 2 years after a live birth and 6 months after early pregnancy loss before conceiving again to reduce the risk of adverse maternal and perinatal outcomes. ${ }^{1}$ This recommendation is based on observational studies, mostly from low/middle-income countries, that have demonstrated associations between short IPI and adverse pregnancy outcomes, ${ }^{2}$ most notably maternal mortality, ${ }^{3}$ small for gestational age (SGA), term low birth weight (LBW), ${ }^{4}$ preterm prelabour rupture of membranes, ${ }^{56}$ preterm 

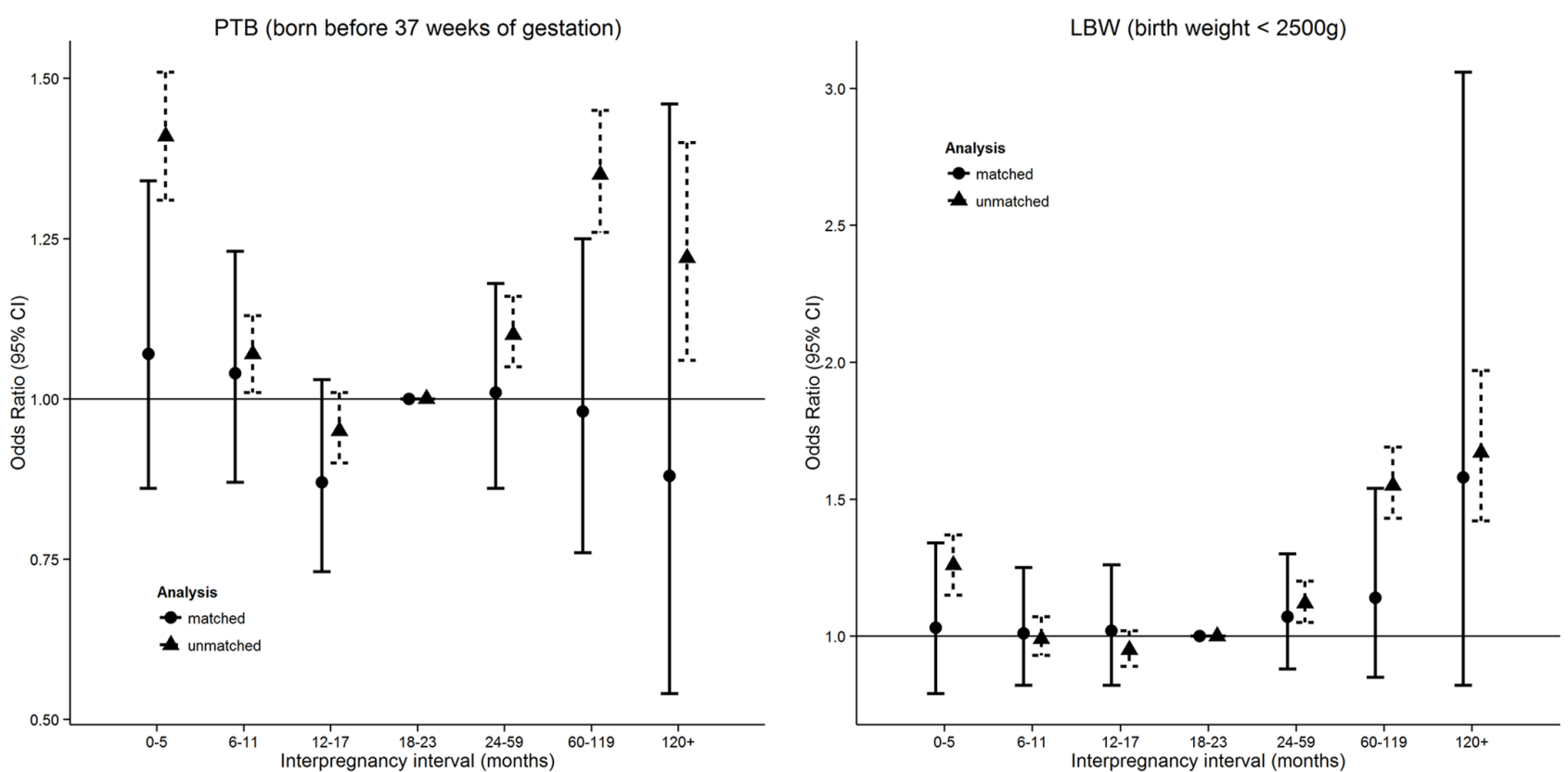

Figure 1 Effects of interpregnancy interval on preterm birth (PTB) and low birth weight (LBW), with and without matching pregnancies to the same women, Western Australia, 1980-2010. Figures produced from statistics reported in Ball et al. $2014^{26}$.

birth (PTB) ${ }^{48}$ and birth defects. ${ }^{910}$ Furthermore, long IPI has been shown to be associated with higher risk of outcomes such as fetal death, ${ }^{11}$ LBW, PTB, SGA ${ }^{12}$ and pre-eclampsia. $^{11} 13$

Several theories have been proposed to explain these associations. Short IPIs may leave insufficient time to recover from maternal nutrient deficits, which can lead to fetal-maternal competition for essential nutrients. ${ }^{14}$ This can be exacerbated by lactation ${ }^{15}$ and malnourishment, in both high-income and low-income countries. ${ }^{1617}$ Short IPIs might also leave insufficient recovery time from inflammatory processes from the previous pregnancy that extend into the next pregnancy. ${ }^{2}$ Long IPIs may result in the loss of adaptive benefits to the mother from a previous birth, resulting in a return to a state equivalent to primigravida. ${ }^{17}$ An alternative hypothesis is that the observed associations between IPI and adverse pregnancy outcomes can be explained, at least partially, by systematic bias. ${ }^{18}$ A spurious association would result if time to conception were independently associated with other factors causally linked to adverse pregnancy outcomes in the subsequent pregnancy. ${ }^{19} 20$ For example, patterns in IPI are associated with maternal age, socioeconomic status (SES), breastfeeding and other antenatal, postnatal or postpartum practices. ${ }^{21} 22$ Furthermore, many factors that can confound the associations between IPI and adverse pregnancy outcomes, such as psychosocial determinants of health, are difficult to measure. Undoubtedly, the greatest challenge for observational studies is to comprehensively account for such confounding factors. High quality studies have adjusted for potential confounders, but statistical adjustment is rarely complete. Residual unmeasured confounding can lead to bias ${ }^{23}$ of the observed effect of IPI on adverse pregnancy outcomes. Importantly, as the mechanisms by which IPI affects specific pregnancy outcomes are not well understood, direct adjustment cannot be made for confounders that remain unknown. Under this scenario, the current state of knowledge on the effects of IPI is clinically unreliable.

In recent years, studies have attempted to address the issue of bias from unmeasured confounding through a matched longitudinal study design. ${ }^{24-26}$ Longitudinal study designs which match pregnancies to the same women $^{2627}$ can better overcome confounding introduced by unknown, unmeasured and inaccurately measured factors that tend to vary between mothers but remain similar between pregnancies. ${ }^{2425} 28$ Findings from these studies suggest the effects of IPI reported from unmatched models are overestimated. Considerable reductions in the U-shape effect of IPI are observed after matching pregnancies to the same women (figure 1 ), ${ }^{26}$ indicating support for the systematic bias hypothesis. These results provide a persuasive argument that some of the IPI effect observed in past studies may be attributable to confounders that vary between women (eg, heritable/genetic, socioeconomic, recurrent health-related behaviour, unknown/ unmeasured), but can be effectively controlled under a longitudinal matched design.

Although these results cast doubt over the adverse effects of IPI, the existence of adverse associations with perinatal outcomes and the optimal IPI period remains unclear due to smaller sample sizes for matched analyses. CIs around estimates are typically wider for matched analyses which rely on women having at least two IPIs during the study period, particularly for the effects of longer IPI (>60 months). In addition, the selection of women with more than two pregnancies in matched analyses limits generalisability to all women. Several other gaps remain in our knowledge around IPI effects (table 1). First, the 
Table 1 Significant gaps in knowledge needed to inform recommendations for optimal interpregnancy interval (IPI) recommendations in high-income countries

\begin{tabular}{ll}
\hline Knowledge gap & Description \\
\hline $\begin{array}{l}\text { What are the IPI effects after } \\
\text { eliminating confounding from } \\
\text { between-women comparisons? }\end{array}$ & $\begin{array}{l}\text { Few past studies have addressed } \\
\text { confounding by matching } \\
\text { pregnancies to the same women. }\end{array}$ \\
$\begin{array}{l}\text { Can IPI effects be observed } \\
\text { later in childhood? }\end{array}$ & $\begin{array}{l}\text { No past studies have investigated } \\
\text { outcomes beyond the neonatal } \\
\text { period, such as hospitalisation in } \\
\text { early childhood. }\end{array}$ \\
$\begin{array}{ll}\text { What are the optimal IPIs for } \\
\text { which risks are minimised? }\end{array}$ & $\begin{array}{l}\text { Although knowledge of harmful } \\
\text { IPls is important, health is }\end{array}$ \\
optimised by identification of \\
optimal IPIs for which risks are \\
minimised.
\end{tabular}

majority of studies have so far been restricted to low-income and middle-income countries. For example, the current WHO recommendation for IPI following early pregnancy loss are based on the findings from a single, albeit large, study in Latin America, and it remains unclear as to whether the findings are relevant to high-income countries. Second, some of the most pertinent questions for women in high-income countries, such as those related to obstetric context, have not yet been addressed. Additional data from high-income countries and more robust results are needed.

\section{Study aims}

The primary aim of this study is to evaluate the impact of IPI on pregnancy outcomes in high-income countries. Secondary aims are to:

1. Evaluate the impact of IPI based on obstetric context: IPI consequences may differ for women based on obstetric history. For example, optimal IPI may vary for women who previously gave birth by caesarean section due to risk of uterine rupture after insufficient time for the uterine scar to heal. ${ }^{29}$ The effect of IPI may also vary depending on gestational age of the previous birth, since longer gestation could be expected to prolong the maternal nutrient deficits and inflammatory processes implicated in poorer outcomes for the subsequent birth, particularly with short IPI. Furthermore, recommendations of IPI after stillbirth require specific attention. ${ }^{30}$ Pregnancy intervals for women following a stillbirth or neonatal loss are approximately 1 year shorter than intervals for women without a loss. ${ }^{31} 32$ It has been speculated that this is due to parents wishing to counter the emotional loss of their infant or to minimise the delay in having a baby. ${ }^{33}$ However, a survey of obstetricians regarding the timing of pregnancy following pregnancy loss found approximately two-thirds of obstetricians endorse women waiting less than 6 months after stillbirth before trying to conceive a new pregnancy. ${ }^{34}$ This is incongruous with WHO IPI recommendations that women wait at least 6 months after pregnancy loss.

2. Evaluate the impact of IPI based on sociodemographic context: The IPI recommendations generated by this study may be most beneficial for those populations for whom we know short IPI and high parity (large family size) is prevalent. Within high-income countries, both family size and the IPI distribution can vary markedly according to race/ethnicity and SES. ${ }^{35} 36$ In this study, we will investigate the effects of IPI among women from different socioeconomic and racial/ethnic groups in multiple high-income countries.

3. Evaluate the potential influence of maternal age on the effect of IPI on pregnancy outcomes: In high-income countries, age at childbirth overall is increasing, with later age at first birth. ${ }^{37-39}$ Systematic reviews conclude that increased maternal age is associated with greater risk of a wide range of adverse obstetric outcomes, ${ }^{40}$ including perinatal mortality, ${ }^{41}$ PTB and $\mathrm{LBW}^{42}$ and pregnancy intervention, particularly caesarean section. ${ }^{43}$ In this study, we will test the hypothesis that there is an interaction between increased maternal age and IPI on the risk of adverse pregnancy outcomes. For each year of maternal age (ie, maternal age at first observed birth in the study period) and for different IPIs, we will calculate the risk of adverse pregnancy outcomes. This will provide valuable information on any combined risks of maternal age and IPI for older women conceiving their second (or later) child.

\section{METHODS AND ANALYSIS}

\section{Study design and population}

We will conduct a longitudinal retrospective cohort study on the effects of IPI on maternal and child health outcomes using individual-level records with near complete coverage of all births $(>99 \%)$ in Australia (Western Australia (WA) and New South Wales (NSW)), Finland, Norway and the USA (California) (table 2).

We will conduct analyses using unmatched (all women) and matched approaches. By matching pregnancies to the same women, we will account for individual-level confounders (known and unknown) that remain stable 
Table 2 Description of cohort and data sources used to identify a cohort of births in four high-income countries

\begin{tabular}{|c|c|c|c|c|c|}
\hline Location & California, USA & Finland & Norway & $\begin{array}{l}\text { New South Wales, } \\
\text { Australia }\end{array}$ & $\begin{array}{l}\text { Western Australia, } \\
\text { Australia }\end{array}$ \\
\hline Time period & 1991-2010 & $1987-2017$ & 1980-2016 & 1994-2016 & 1980-2015 \\
\hline Data source & $\begin{array}{l}\text { Office of Statewide } \\
\text { Health Planning and } \\
\text { Development (OSHPD) }\end{array}$ & $\begin{array}{l}\text { National Institute for } \\
\text { Health and Welfare } \\
\text { (THL), Medical Birth } \\
\text { Register }\end{array}$ & $\begin{array}{l}\text { Norwegian Institute of } \\
\text { Public Health, Medical } \\
\text { Birth Registry }\end{array}$ & $\begin{array}{l}\text { NSW Perinatal Data } \\
\text { Collection, NSW } \\
\text { Ministry of Health }\end{array}$ & $\begin{array}{l}\text { WA Midwives Data } \\
\text { Collection, WA } \\
\text { Department of Health }\end{array}$ \\
\hline Information available & $\begin{array}{l}\text { Maternal } \\
\text { characteristics and } \\
\text { health conditions; } \\
\text { smoking and } \\
\text { BMI (2007-2010); } \\
\text { pregnancy and labour } \\
\text { conditions, antenatal } \\
\text { hospitalisations, } \\
\text { information on delivery } \\
\text { and birth outcomes; } \\
\text { gestational age based } \\
\text { on LMP estimate } \\
\text { (obstetric estimate } \\
\text { available for years } \\
\text { 2007-2010) }\end{array}$ & $\begin{array}{l}\text { Maternal } \\
\text { characteristics and } \\
\text { health conditions; } \\
\text { smoking; pregnancy } \\
\text { and labour } \\
\text { complications; } \\
\text { pregnancy history; } \\
\text { details of antenatal } \\
\text { care; information on } \\
\text { delivery and birth } \\
\text { outcomes; health of } \\
\text { infant at discharge or } \\
7 \text { days }\end{array}$ & $\begin{array}{l}\text { Maternal } \\
\text { characteristics and } \\
\text { health conditions; } \\
\text { pregnancy and } \\
\text { labour complications; } \\
\text { medication use during } \\
\text { pregnancy; birth } \\
\text { outcomes; diagnoses } \\
\text { of congenital } \\
\text { abnormalities; } \\
\text { parental occupation } \\
\text { and smoking; births } \\
\text { following assisted } \\
\text { conception }\end{array}$ & $\begin{array}{l}\text { Maternal } \\
\text { characteristics and } \\
\text { health conditions; } \\
\text { smoking; pregnancy } \\
\text { and labour } \\
\text { complications; details } \\
\text { of labour; birth } \\
\text { outcomes; congenital } \\
\text { anomalies, infant and } \\
\text { child health outcomes }\end{array}$ & $\begin{array}{l}\text { Maternal } \\
\text { characteristics and } \\
\text { health conditions; } \\
\text { smoking; pregnancy } \\
\text { and labour } \\
\text { complications; details } \\
\text { of labour; birth } \\
\text { outcomes; congenital } \\
\text { anomalies, infant and } \\
\text { child health outcomes }\end{array}$ \\
\hline $\begin{array}{l}\text { Scope of notified } \\
\text { births }\end{array}$ & $\begin{array}{l}\text { All live births } \\
\text { and stillbirths } \\
\text { with gestational } \\
\text { length } \geq 20 \text { weeks }\end{array}$ & $\begin{array}{l}\text { All live births } \\
\text { and stillbirths } \\
\text { with gestational } \\
\text { length } \geq 22 \text { weeks or } \\
\text { birth weight } \geq 500 \mathrm{~g}\end{array}$ & $\begin{array}{l}\text { All pregnancies ending } \\
\text { after week } 12 \text { from } \\
2002 \text { onwards (from } \\
\text { week } 16 \text { from } 1980 \text { to } \\
\text { 2001) }\end{array}$ & $\begin{array}{l}\text { Gestational } \\
\text { length } \geq 20 \text { weeks or } \\
\text { birth weight } \geq 400 \mathrm{~g}\end{array}$ & $\begin{array}{l}\text { Gestational } \\
\text { length } \geq 20 \text { weeks or } \\
\text { birth weight } \geq 400 \mathrm{~g}\end{array}$ \\
\hline Linkage methods & $\begin{array}{l}\text { Probabilistic linkage } \\
\text { based on maternal } \\
\text { descriptors }\end{array}$ & $\begin{array}{l}\text { Deterministic linkage } \\
\text { of mother based on } \\
\text { personal ID }\end{array}$ & $\begin{array}{l}\text { Deterministic linkage } \\
\text { of mother based on } \\
\text { personal ID }\end{array}$ & $\begin{array}{l}\text { Probabilistic linkage } \\
\text { based on maternal } \\
\text { descriptors }\end{array}$ & $\begin{array}{l}\text { Probabilistic linkage } \\
\text { based on maternal } \\
\text { descriptors }\end{array}$ \\
\hline Total births & 10.9 million & 1.8 million & 2.1 million & 2.2 million & 1.2 million \\
\hline
\end{tabular}

BMI, body mass index; LBW, low birth weight; LMP, last menstrual period; PTB, preterm birth.

between pregnancies. The effect of IPI from matched and unmatched analyses will be compared. The study's population will consist of more than 18 million births, which will be the largest IPI study for high-income countries. The size of this cohort offers several advantages, as it allows us to: (1) investigate IPI effects among subpopulations, and (2) ensure the best possible control for confounding. Where within-mother matching is not possible (eg, when studying effect modification, sample size in individual data categories becomes reduced), we will match on propensity scores. ${ }^{44}$

\section{Inclusion criteria}

Women with two or more consecutive pregnancies will be included in the study. The target population for inference includes women with $>1$ birth during their life course. IPI is not relevant for women who have only one birth. Given that matching pregnancies to the same women requires $>1$ pregnancy interval per woman, the cohort for matched analyses will be restricted to women who have two or more births during the study period. The 20-year to 30-year study period ensures sufficient follow-up to observe final family size. Birth status (live born vs stillborn), plurality (singleton vs multiple) and maternal age will inform inclusion criteria for specific hypotheses.

\section{Definition of IPI}

IPI will be defined as the length of time between the start of the index pregnancy (birth date minus gestational length) and the birth date of the preceding pregnancy. IPI will be classified using integer months and categorised as: $0-5,6-11,12-17,18-23,24-59,60-119$ and $\geq 120$ months, with 18-23 months used as the referent group. ${ }^{26}$ These intervals share endpoints consistent with recommendations of past studies and WHO recommendations. In addition, IPI will be considered as a continuous variable for assessment of optimal IPI.

\section{IPI-relevant health outcomes}

Based on a review of the current literature, we identified a set of clinically significant IPI-relevant endpoints, contexts and competing risks that can be investigated accurately and reliably (see online supplementary table S1). We classified the primary IPI-relevant endpoints into the following two categories: PTB; and fetal growth restriction based on the definitions of SGA and LBW. Additional 


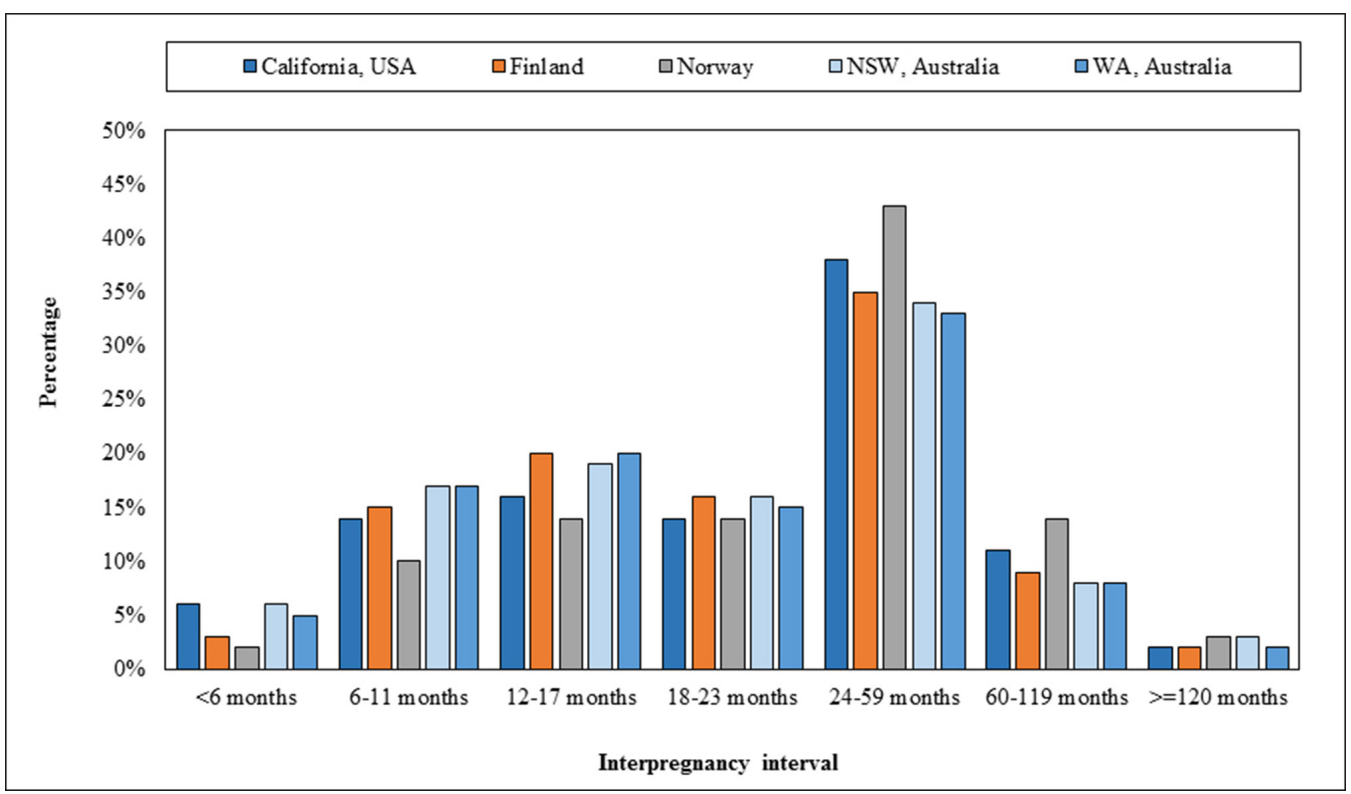

Figure 2 Distribution of interpregnancy interval following a live birth, by country/state-1980-2016.

endpoints include congenital anomaly; complications of pregnancy and labour; infant and child health outcomes; and perinatal, infant and maternal mortality.

\section{Data sources}

Cohorts will be assembled from linked birth cohort files in California with Office of Statewide Health Planning and Development maternal and infant hospital discharge data (USA: 1991-2010); the National Institute for Health and Welfare (THL), Medical Birth Register (Finland: 19872017); the Norwegian Institute of Public Health, Medical Birth Registry (Norway: 1980-2015); the NSW Perinatal Data Collection, NSW Ministry of Health (Australia: 19942016); and the WA Midwives Data Collection, WA Department of Health (Australia: 1980-2015) (table 2). Coverage is $>99 \%$ of births for each country/jurisdiction. IPIs for each data source will be derived (figure 2), and maternal characteristics and health conditions, pregnancy complications, details of labour and childbirth, birth outcomes and mortality will be identified (see online supplementary table S1). Some sites will have access to additional linked hospital and child development data, offering the opportunity to explore the impact on additional maternal and child health outcome measures, including congenital anomalies (WA, NSW, Norway, Finland) and hospital admissions (WA, NSW, Finland).

\section{Data deidentification and secure storage}

Deidentified data from California and Finland will be retained and held securely at those sites; deidentified data from Norway, WA and NSW will be transferred to and stored at the School of Public Health, Curtin University. Project data will be electronically stored on a secure server, which is backed up daily to prevent any unintentional data loss. The research environment includes a variety of security controls to restrict unauthorised access-these include access controls, role-based delegations, encryption, firewalls and physical access restrictions (authorised access to server rooms and research offices is restricted by key). Automatic screen locking will occur on electronic devices after 5 min of inactivity. Data will not be stored or used in public terminals. No paper-based or portable electronic media storage of data will take place.

\section{Statistical methods}

Matched and unmatched logistic regression will be used to investigate all maternal and child health outcomes (see online supplementary table S1). For primary analyses, mother ID will be used as the matching variable to identify strata. This method ensures that the results will be based entirely on within-women (not betweenwomen) comparisons, minimising the need for additional adjustment and is the standard statistical method for matched studies. We will explicitly adjust for factors of the index pregnancy that do/can change between pregnancies. Specifically, we will adjust for maternal age (categorical variable: 14-19, 20-24, 25-29, 30-34, 35-39 and $\geq 40$ years), parity (categorical) and conception year (non-linear spline). Due to differences between countries in the completeness and method of measurement of SES (or maternal education as a proxy), adjustment for SES will not be possible when data are pooled across countries, but may be undertaken when analyses are conducted using single-country data sets.

Matched analyses will be undertaken to address secondary aims, where possible. In circumstances where within-mother matching is not feasible or not possible (eg, subpopulations with small sample sizes which would be further restricted by requiring more than two consecutive pregnancies per mother), unmatched models or alternative matching methods will be used (eg, propensity score stratification; sibling-matched methods using a single IPI). ${ }^{844} 45$ 
Analyses will first be applied to each site's data individually. The analytic approach and statistical code used for data sets held at Curtin University (WA, NSW, Norway) will be sent to the other sites (California, Finland) to replicate analyses, allowing standardisation and minimising methodological heterogeneity between countries. ${ }^{46}$ Meta-analysis ${ }^{47}$ will be used to combine adjusted ORs obtained from each data source into a single pooled estimate generalisable to high-income countries. Heterogeneity between countries will be investigated with the $\mathrm{I}^{2}$ statistic. ${ }^{48}$

\section{Patient and public involvement}

A reference group of consumer health representatives (Healthy Pregnancies Reference Group) has been established, and will meet twice-yearly to provide a community perspective on this research. The reference group will provide advice regarding the aims of the research; language, including lay summaries; links between consumers, the community and the researchers; and advocacy on behalf of consumers and the community. The reference group will also contribute consumer perspectives on potential utilisation of the research findings, such as the identification of factors that may influence IPI (see online supplementary table S2), with the intention to inform further primary research in this area.

\section{ETHICS AND DISSEMINATION}

\section{Human research ethics committee approval}

This research has ethics approval from ethics committees at participating sites. Each committee provided a waiver of consent for participants. For Finland, ethical approval was not required.

\section{Intended publications and research dissemination}

Data sets generated and/or analysed during the current study are not publicly available due to data confidentiality agreements with data custodians. Results generated by the research will be made publicly available at the summary level. Standalone manuscripts addressing primary and secondary aims will be published in peer-reviewed journals. Results will also be presented at relevant perinatal and epidemiological conferences. Findings will be used to develop guidelines for IPI as a potentially modifiable risk factor linked to adverse perinatal outcomes, specifically for women in high-income countries.

\section{DISCUSSION}

This study will inform new IPI recommendations for women in high-income countries. Recommendations will be specific to obstetric and socioeconomic context. By combining record-linked perinatal data from multiple countries-Australia, Finland, Norway and the USA - this study will achieve the largest sample of high-quality health data in high-income countries. Novel methodology, matching pregnancies to the same women, will achieve the best control for confounding of any study to date.
This international cohort approach offers several advantages. Large sample sizes are required to undertake matched analyses with adequate statistical power to detect clinically meaningful differences between IPIs. Prospective studies of this size are infeasible. This study can only be achieved using linked perinatal data within an international collaboration. Collaboration to standardise methods between countries will also minimise methodological heterogeneity in pooled analyses. Furthermore, this research has the potential to be extended by broadening the collaboration to incorporate additional data sets. The minimum data requirements for contributing to this project are: (1) unique identifier for mothers to link multiple pregnancies; (2) mother's date of birth; (3) child's date of birth; (4) child's gestational length; and (5) other birth and early childhood outcomes as described in online supplementary table S1. Researchers interested in joining this collaboration are encouraged to contact us through the corresponding author.

This information is essential for supporting family planning, both at the patient and provider level. Evidence-based recommendations for IPI for women in high-income countries are useful for assisting families when planning future pregnancies and for clinicians when providing intrapregnancy counselling.

\section{Author affiliations}

${ }^{1}$ School of Public Health, Curtin University, Bentley, Western Australia, Australia ${ }^{2}$ School of Public Health, Texas A and M University, College Station, Texas, USA ${ }^{3}$ Information Services Department, National Institute for Health and Welfare, Helsinki, Finland

${ }^{4}$ Department of Neurobiology, Care Sciences and Society, Karolinska Institute, Stockholm, Sweden

${ }^{5} \mathrm{MRC}$ Integrative Epidemiology Unit, University of Bristol, Bristol, UK

${ }^{6}$ Population Health Sciences, Bristol Medical School, Bristol, UK

${ }^{7}$ Centre for Fertility and Health (CeFH), Norwegian Institute of Public Health, Oslo, Norway

${ }^{8}$ Department of Obstetrics, Gynecology and Reproductive Sciences, University of California, San Francisco, California, USA

${ }^{9}$ Department of Pediatrics, Stanford University, Stanford, California, USA

${ }^{10}$ School of Nursing, Midwifery and Paramedicine, Curtin University, Perth, Western Australia, Australia

${ }^{11}$ Menzies Centre for Health Policy, School of Public Health, University of Sydney, Sydney, New South Wales, Australia

${ }^{12}$ Faculty of Public Health and Policy, London School of Hygiene and Tropical Medicine, London, UK

${ }^{13}$ Telethon Kids Institute, University of Western Australia, Subiaco, Western Australia, Australia

${ }^{14}$ UNDP/UNFPA/UNICEF/WHO/World Bank Special Programme of Research, Development and Research Training in Human Reproduction, Department of Reproductive Health and Research, World Health Organization, Geneva, Switzerland

Acknowledgements The authors would like to thank the Linkage and Client Services Teams at the Data Linkage Branch (Department of Health Western Australia) as well as the Data Custodian for the Midwives Notification System. The authors would also like to thank members of the Healthy Pregnancies Consumer Reference Group who provided community input and guidance in this research.

Contributors GFP, SB, AKR and MLM conceived the idea, planned and designed the study protocol. GFP, SB, AKR, MLM, MG, MCM, SEH, AMP, JAM, GMS, EM, ATG, NN, CM, NdK and APB contributed to the development of the protocol, study design and methods. MLM and AKR wrote the first draft. MG, MCM, SEH, AMP, JAM, GMS, SB, EM, ATG, NN, CM, NdK, AMP and GFP critically revised the draft for important intellectual content. All authors have approved the final written manuscript. 
Funding This work was supported by funding from the National Health and Medical Research Council, including an Early Career Fellowship [\#GNT1138425 to AR], Senior Research Fellowship [\# 1117105 to HL], Career Development Fellowship [\#APP1067066 to NN] and project grants [\#1099655 to GP, NN, SJB; \#APP1141510 to AR, GP]. MCM works at the MRC Integrative Epidemiology Unit at the University of Bristol which receives infrastructure funding from UK Medical Research Council (MC/UU/12013/5), and she is also supported by the following fellowship from the UK Medical Research Council (MR/M009351/1). This work was partly supported by the Research Council of Norway through its Centres of Excellence funding scheme, project number 262700 .

Competing interests None declared.

Patient consent for publication Not required.

Ethics approval This study was approved by the Department of Health Western Australia Human Research Ethics Committee; Curtin University Human Research Ethics Committee; NSW Population and Health Services Research Ethics Committee; Stanford University Institutional Review Board; and the Norwegian Regional Committees for Medical and Health Research Ethics. Each committee provided a waiver of consent for participants.

Provenance and peer review Not commissioned; peer reviewed for ethical and funding approval prior to submission.

Open access This is an open access article distributed in accordance with the Creative Commons Attribution 4.0 Unported (CC BY 4.0) license, which permits others to copy, redistribute, remix, transform and build upon this work for any purpose, provided the original work is properly cited, a link to the licence is given, and indication of whether changes were made. See: https://creativecommons.org/ licenses/by/4.0/.

\section{REFERENCES}

1. Marston C. Report of a WHO technical consultation on birth spacing. Geneva Switzerland: World Health Organization, 2007.

2. Shachar BZ, Lyell DJ. Interpregnancy interval and obstetrical complications. Obstet Gynecol Surv 2012;67:584-96.

3. Conde-Agudelo A, Belizán JM. Maternal morbidity and mortality associated with interpregnancy interval: cross sectional study. BMJ 2000;321:1255-9.

4. Conde-Agudelo A, Belizán JM, Norton MH, et al. Effect of the interpregnancy interval on perinatal outcomes in Latin America. Obstet Gynecol 2005;106:359-66.

5. Getahun D, Strickland D, Ananth CV, et al. Recurrence of preterm premature rupture of membranes in relation to interval between pregnancies. Am J Obstet Gynecol 2010;202:570.e1-6.

6. Razzaque A, Da Vanzo J, Rahman M, et al. Pregnancy spacing and maternal morbidity in Matlab, Bangladesh. Int J Gynaecol Obstet 2005;89:S41-9.

7. Smith GC, Pell JP, Dobbie R. Interpregnancy interval and risk of preterm birth and neonatal death: retrospective cohort study. BMJ 2003;327:313.

8. Regan AK, Ball SJ, Warren JL, et al. A population-based matched sibling analysis estimating the association between first interpregnancy interval and birth outcomes. Am J Epidemiol 2018.

9. Grisaru-Granovsky S, Gordon ES, Haklai Z, et al. Effect of interpregnancy interval on adverse perinatal outcomes--a national study. Contraception 2009;80:512-8.

10. Kwon S, Lazo-Escalante M, Villaran MV, et al. Relationship between interpregnancy interval and birth defects in Washington State. $J$ Perinatol 2012;32:45-50.

11. Mignini LE, Carroli G, Betran AP, et al. Interpregnancy interval and perinatal outcomes across Latin America from 1990 to 2009: a large multi-country study. BJOG 2016;123:730-7.

12. Conde-Agudelo A, Rosas-Bermúdez A, Kafury-Goeta AC. Birth spacing and risk of adverse perinatal outcomes: a meta-analysis. JAMA 2006;295:1809-23.

13. Cormick G, Betrán AP, Ciapponi A, et al. Inter-pregnancy interval and risk of recurrent pre-eclampsia: systematic review and meta-analysis. Reprod Health 2016;13:83.

14. Winkvist A, Rasmussen KM, Habicht JP. A new definition of maternal depletion syndrome. Am J Public Health 1992;82:691-4.

15. Adair LS, Popkin BM. Prolonged lactation contributes to depletion of maternal energy reserves in Filipino women. $J$ Nutr 1992;122:1643-55.

16. Adam I, Ismail MH, Nasr AM, et al. Low birth weight, preterm birth and short interpregnancy interval in Sudan. J Matern Fetal Neonatal Med 2009;22:1068-71.
17. Zhu BP, Rolfs RT, Nangle BE, et al. Effect of the interval between pregnancies on perinatal outcomes. N Engl J Med 1999;340:589-94.

18. Miller JE. Birth intervals and perinatal health: an investigation of three hypotheses. Fam Plann Perspect 1991;23:62-70.

19. Sholapurkar SL. Is there an ideal interpregnancy interval after a live birth, miscarriage or other adverse pregnancy outcomes? J Obstet Gynaecol 2010;30:107-10.

20. Thom DH, Nelson LM, Vaughan TL. Spontaneous abortion and subsequent adverse birth outcomes. Am J Obstet Gynecol 1992;166:111-6.

21. Flacking R, Nyqvist KH, Ewald U. Effects of socioeconomic status on breastfeeding duration in mothers of preterm and term infants. Eur $J$ Public Health 2007;17:579-84.

22. Blakely T, Hunt D, Woodward A. Confounding by socioeconomic position remains after adjusting for neighbourhood deprivation: an example using smoking and mortality. J Epidemiol Community Health 2004;58:1030-1.

23. Kaufman JS, Cooper RS, McGee DL. Socioeconomic status and health in blacks and whites: the problem of residual confounding and the resiliency of race. Epidemiology 1997;8:621-8.

24. Shachar BZ, Mayo JA, Lyell DJ, et al. Interpregnancy interval after live birth or pregnancy termination and estimated risk of preterm birth: a retrospective cohort study. BJOG 2016;123:2009-17.

25. Hanley GE, Hutcheon JA, Kinniburgh BA, et al. Interpregnancy interval and adverse pregnancy outcomes: an analysis of successive pregnancies. Obstet Gynecol 2017;129:408-15.

26. Ball SJ, Pereira G, Jacoby P, et al. Re-evaluation of link between interpregnancy interval and adverse birth outcomes: retrospective cohort study matching two intervals per mother. $B M J$ 2014;349:g4333.

27. Pereira G, Bell ML, Lee HJ, et al. Sources of fine particulate matter and risk of preterm birth in Connecticut, 2000-2006: a longitudinal study. Environ Health Perspect 2014;122:1117-22.

28. Susser E, Eide MG, Begg M. Invited commentary: the use of sibship studies to detect familial confounding. Am J Epidemiol 2010:172:537-9.

29. Conde-Agudelo A, Rosas-Bermúdez A, Kafury-Goeta AC. Effects of birth spacing on maternal health: a systematic review. Am J Obstet Gynecol 2007;196:297-308.

30. Regan AK, Gissler M, Magnus MC, et al. Adverse birth outcomes associated with interpregnancy interval among women with a previous stillbirth: an international cohort study: Lancet in press.

31. August EM, Salihu HM, Weldeselasse $\mathrm{H}$, et al. Infant mortality and subsequent risk of stillbirth: a retrospective cohort study. BJOG 2011;118:1636-45.

32. Black M, Shetty A, Bhattacharya S. Obstetric outcomes subsequent to intrauterine death in the first pregnancy. BJOG 2008;115:269-74

33. Rowland Hogue CJ, Silver RM. Racial and ethnic disparities in United States: stillbirth rates: trends, risk factors, and research needs. Semin Perinatol 2011;35:221-33.

34. Gold KJ, Leon I, Chames MC. National survey of obstetrician attitudes about timing the subsequent pregnancy after perinatal death. Am J Obstet Gynecol 2010;202:357.e1-6.

35. Hogue CJ, Menon R, Dunlop AL, et al. Racial disparities in preterm birth rates and short inter-pregnancy interval: an overview. Acta Obstet Gynecol Scand 2011;90:1317-24.

36. Khoshnood B, Lee KS, Wall S, et al. Short interpregnancy intervals and the risk of adverse birth outcomes among five racial/ethnic groups in the United States. Am J Epidemiol 1998;148:798-805.

37. Blickstein I. Motherhood at or beyond the edge of reproductive age. Int J Fertil Womens Med 2003:48:17-24.

38. Hilder L, Zhichao Z, Parker M, et al. Australia's mothers and babies 2012. Perinatal statistics series no. 30. Canberra: AlHW National Perinatal Epidemiology and Statistics Unit, 2014.

39. Matthews TJ, Hamilton BE. First births to older women continue to rise. NCHS Data Brief 2014;152:1-8.

40. Usta IM, Nassar AH. Advanced maternal age. Part I: obstetric complications. Am J Perinatol 2008;25:521-34.

41. Huang L, Sauve R, Birkett N, et al. Maternal age and risk of stillbirth: a systematic review. CMAJ 2008;178:165-72.

42. Carolan M. Maternal age $\geq 45$ years and maternal and perinatal outcomes: a review of the evidence. Midwifery 2013;29:479-89.

43. Bayrampour $\mathrm{H}$, Heaman M. Advanced maternal age and the risk of cesarean birth: a systematic review. Birth 2010;37:219-26.

44. D'Agostino RB. Propensity score methods for bias reduction in the comparison of a treatment to a non-randomized control group. Stat Med 1998;17:2265-81.

45. Cheslack-Postava K, Liu K, Bearman PS. Closely spaced pregnancies are associated with increased odds of autism in California sibling births. Pediatrics 2011;127:246-53. 
46. Riley RD, Lambert PC, Abo-Zaid G. Meta-analysis of individual participant data: rationale, conduct, and reporting. $B M J$ 2010;340:c221.

47. Egger M, Smith GD, Phillips AN. Meta-analysis: principles and procedures. BMJ 1997;315:1533-7.
48. Higgins JP, Thompson SG, Deeks JJ, et al. Measuring inconsistency in meta-analyses. BMJ 2003;327:557-60.

49. Dildy GA, Jackson GM, Fowers GK, et al. Very advanced maternal age: pregnancy after age 45. Am J Obstet Gynecol 1996;175:668-74. 